\title{
A GRAMÁTICA DO ACASO: ANÁLISE, ALEATORIEDADE E INDETERMINISMO NO SEGUNDO WITTGENSTEIN*
}

\author{
Mauro Lúcio Leitão Condé
}

\begin{abstract}
Resumo
O objetivo deste capítulo é demonstrar como "aleatoriedade" e "indeterminismo" podem ser vistos na filosofia da linguagem do segundo Wittgenstein, em especial, a partir de sua noção de análise da linguagem. Em outros termos, procuro demonstrar como a análise da gramática e de seus jogos de linguagem permite não apenas realizar uma "terapêutica" dos mal-entendidos que conduzem à metafísica, mas também perceber, a partir de sua dimensão "panorâmica", as regularidades já instituídas nas regras gramaticais, além de dar acesso e entendimento ao novo que se configura no horizonte como acaso (exceções) e ao que se coloca como indeterminado (enquanto um não regramento da gramática).
\end{abstract}

Palavras-chaves: Wittgenstein; Gramática; Acaso; Indeterminismo; Aleatoriedade

\section{1- Introdução}

Para demonstrar como "acaso", "aleatoriedade" e "indeterminismo" podem ser compreendidos na filosofia da linguagem do segundo Wittgenstein, ${ }^{1}$ considerando sua noção de análise da linguagem, parto do pressuposto de que a análise não se constitui apenas como uma "terapêutica da linguagem" para desconstruir a metafísica - como enfatizado pela tradição da filosofia analítica - , mas também fornece, por meio de um aspecto panorâmico, acesso a um tipo de "constituição ontológica". Com efeito, tomo como princípio que, para Wittgenstein, "a essência está expressa na gramática” (IF \ 371) 2 e apenas, como procurarei mostrar, por meio da análise panorâmica podemos apreendêla. Mais que o parâmetro de compreensão das regularidades das regras instituídas (o que está de acordo com a gramática e o que não está), a análise panorâmica também é o instrumento que nos permite lidar com o acaso e o indeterminado que se apresentam nas bordas da gramática.

Para compreendermos em que medida podemos pensar a articulação entre os conceitos de análise, acaso (aleatoriedade) e indeterminismo no segundo Wittgenstein, torna-se necessário compreendermos como a sua filosofia da linguagem se articula a partir da noção de gramática. A gramática constitui um modelo de racionalidade a partir do qual realizamos os julgamentos de nossas ações e interações com os objetos nos nossos jogos

\footnotetext{
* DOI - 10.29388/978-65-86678-51-2-0-f.199-212

${ }^{1}$ Tornou-se comum entre os intérpretes do filósofo austríaco denominar seu pensamento de maturidade de "segundo Wittgenstein". A abordagem aqui desenvolvida se refere à esta segunda fase do pensamento de Wittgenstein caracterizada, sobretudo, pelas Investigaçôes Filosóficas.

2 A partir deste ponto irei me referir aos textos de Wittgenstein aqui trabalhados da seguinte forma: As Investigações Filosóficas, nas citações, IF \, seguidas do número do parágrafo a que se referem. O Sobre a Certęa, nas citações, SC \, seguido do número do aforismo a que se refere. O Tractatus Logico-Pbilosophicus, nas citações, Tract., seguido do número do aforismo a que se refere.
} 
de linguagem (Sprachspiele) (IF \ 7), posto que, para o autor das Investigações Filosóficas, nossas ações são regradas e "que espécie de objeto alguma coisa é, é dito pela gramática" (IF S 373). Deste modo, enquanto regramento, a gramática se estabelece como nosso "sistema de referência" (IF \ 206) para a compreensão dos jogos de linguagem nos quais encontramos "regularidades" e "exceções". Dito de outro modo, na gramática, a própria exceção confirma a regra consolidando assim a regularidade dos jogos. $\mathrm{O}$ conhecimento dessa distinção entre regularidades e exceções é possibilitado pela análise.

Embora na gramática esteja presente essas regularidades ou regramentos com as quais julgamos o mundo, muitos dos fenômenos com os quais lidamos são absolutamente novos, ou são fenômenos aleatórios, até então, não presentes em nossa gramática. Alguns desses novos fenômenos aleatórios são integrados à gramática na medida em que se tornam constantes e passamos a detectar suas regularidades. Contudo, outros tantos fenômenos anômalos - não necessariamente frutos do acaso, além de serem constantes não se incorporam em nossas regularidades sendo, assim, indeterminados, segundo as regras da gramática. Mais que isso, a própria dinâmica da gramática comporta o espaço do "não regramento" ou desta indeterminação. Ainda assim, a partir da gramática há a possibilidade de compreender muitos de tais acasos e aleatoriedades e, em certa medida, como veremos à frente, pelo menos, qualificar a indeterminação (a partir do que é regrado determinar o não regrado). Enfim, é a partir da gramática que compreendemos o que é determinado e o que não é, isto é, o que é regular, mas também o que é indeterminando, aleatório ou fruto do próprio acaso. O ponto principal aqui defendido é o de que, em uma perspectiva wittgensteiniana, a chave para a compreensão do acaso e do indeterminismo é a noção de análise. Através da análise compreendemos o real lugar de uma regra gramatical não apenas eliminando possíveis faltas de compreensão que conduzem a erros e interpretações metafísicas, mas também "determinando" as regularidades e mesmo as exceções.

A análise, assim, se presta à um duplo papel ou função: 1) a função "terapêutica" que visa eliminar erros linguísticos e construções metafísicas; 2) a função "panorâmica" que nos mostra a articulação do conjunto das regras que sustentam a gramática e, por conseguinte, também mostra o que é aleatório ou indeterminado nos limites da gramática. Dito de outro modo, em sua função terapêutica, a análise nos mostra o que está errado ou não regrado de acordo com a gramática - possibilitando, assim, realizarmos uma terapia. Em sua função panorâmica, a análise nos dá acesso às diferentes possibilidades da gramática, isto é, nos faculta o acesso, em termos wittgensteinianos, à essência que está expressa na gramática (IF $\int 371$ ). Contudo, é importante salientar que essa função panorâmica da análise não nos dá acesso propriamente a um fato ou fenômeno, mas às "considerações gramaticais" que fazemos sobre os fenômenos (IF \ 90). Ela é, sobretudo, uma análise gramatical. Este é o ponto central do que aqui chamo de análise panorâmica ou análise da constituição gramatical. Essa análise nos mostra as muitas e diferentes possibilidades de articulação da gramática de onde provêm a inteligibilidade com a qual damos sentido ao que ocorre em nossa forma de vida.

Resta reforçar que não existe uma diferença de natureza entre estes dois aspectos da análise, mas, como salientado, de função, isto é, dependendo do que queremos aferir, podemos enfatizar um aspecto ou outro da análise. Contudo, muitas vezes, os intérpretes de Wittgenstein ignoraram a função panorâmica em detrimento de uma ênfase da função 
terapêutica. Essa diferenciação das funções da análise é algo que, a meu ver, separou Wittgenstein de outros pensadores da filosofia da linguagem ordinária. Como essa perspectiva terapêutica da análise está amplamente arraigada na filosofia analítica, a questão da análise nas Investigações Filosóficas foi vista majoritariamente por este prisma. ${ }^{3}$

Em parte, essa não distinção de diferentes funções da análise se deveu não apenas à dificuldade de interpretação do pensamento de Wittgenstein, mas mesmo à uma dificuldade de tradução da língua alemã, em especial, relativamente a todos os conceitos que envolvam a palavra "panorâmico", tais como: "apresentação panorâmica" (übersichtliche Darstellung); "visão panorâmica" (übersehen); "dimensão panorâmica" (übersichtlichkeit) que também podem ser traduzidas por "apresentação clara" (übersichtliche Darstellung); "clara visão" (übersehen); "disposição clara” (übersichtlichkeit). Entendo que aqueles intérpretes que quiseram ver o aspecto terapêutico como mais incisivo optaram pela tradução que enfatiza a ideia de clareza. Por outro lado, os tradutores e intérpretes que optaram por traduzir übersicbtliche por panorâmico acabam por reforçar a ideia de uma função panorâmica da análise. $^{4}$

Para demostrar como a análise apresenta essa dupla função na perspectiva do segundo Wittgenstein, em um primeiro momento, ainda que de modo resumindo, faz-se necessário compreender a sua noção de gramática. Assim, procurarei, inicialmente, mostrar como a gramática constitui um modelo de racionalidade a partir do qual construímos nossos julgamentos. Em seguida, abordarei esses dois aspectos da análise no contexto da gramática, isto é, a análise terapêutica e a análise panorâmica. Torna-se muito importante pensar a questão do acaso e do indeterminado em relação à análise panorâmica porque, para além da função terapêutica da análise, é por sua função panorâmica que podemos compreender a inserção de novas informações na nossa gramática e, assim, remodelá-la e ampliar nosso conhecimento, seja compreendendo aspectos regulares não claros na gramática ou, mais que isso, estabelecendo o lugar do indeterminado ou do aleatório. Com efeito, avançar sobre o aleatório e o indeterminado são possibilidades de ampliação do conhecimento. Em certo sentido, pela análise terapêutica conhecemos melhor o que já sabemos (a terapia pressupõe o conhecimento de uma certa ordem de correção dada previamente pela gramática), contudo, pela análise panorâmica, podemos não apenas compreender a extensão do nosso conhecimento (limites da gramática), mas expandi-lo ao conectar com o que ainda não era sabido, por exemplo, o aleatório ou o indeterminado.

\section{2- A Gramática e os Jogos de Linguagem}

Embora Wittgenstein não seja considerado um filósofo sistemático, em alguma medida, sua segunda filosofia presente nas Investigações Filosóficas elabora um certo tipo de

\footnotetext{
3 O simples fato desta função terapêutica já se aproximar de um tipo de "ontologia" em Wittgenstein (a essência expressa na gramática), distanciou os intérpretes da filosofia analítica desta leitura aqui proposta que compreende diferentes funções da análise nas Investigações Filosóficas.

${ }^{4}$ Essa dificuldade se apresenta não apenas nas traduções de Wittgenstein para o português, mas também para outras línguas como o inglês e o francês. As duas traduções brasileiras das Investigações Filosóficas fizeram escolhas diferentes. M. G. Montagnoli utiliza "clara visão" (übersehen) e "disposição clara" (übersichtlichkeit). Cf. (Wittgenstein, 1994, \ 122). J. C. Bruni optou por "visão panorâmica" (übersehen) e "caráter panorâmico" (übersichtlichkeit). Cf. (Wittgenstein, 1979, \ 122). $\mathrm{Na}$ tradução para o inglês, M. Anscombe utiliza "clear view" (übersehen) e "perspicuity" (übersichtlichkeit). Cf. (Wittgenstein, 2008, \ 122). Na tradução para o francês, Klossowisky traduziu por "globale" (übersichtliche), algo mais próximo de panorâmico. Cf. (Wittgenstein, 1961 \122).
} 
sistema em que a noção de gramática pode ser compreendida como um elemento articulador. Em Wittgenstein, os conceitos de uso, jogos de linguagem, semelhanças de família, seguir a regra, etc., ${ }^{5}$ em suas múltiplas e diversas interações e articulações possibilitam a emergência da gramática. Em outras palavras, é este conjunto da linguagem, dos objetos, das ações e comportamentos - revelando assim a perspectiva pragmática adotada por nosso autor - que possibilita a gramática enquanto o conjunto das regras geradas no "solo áspero" dos jogos de linguagem. A gramática é fruto da pragmática. Esta concepção nasce da ideia de que, para Wittgenstein, compreender o significado de uma palavra não é encontrar um objeto no mundo e denominá-lo, mas estabelecer sua significação a partir do uso que fazemos de uma palavra e das regras linguísticas e pragmáticas que a rege em diferentes situações e ocorrências. Como salientado por Wittgenstein, "[...] a significação de uma palavra é seu uso na linguagem" (IF \43). Vemos assim que, diferentemente da tradição filosófica, e mesmo do primeiro Wittgenstein do Tractatus Logico Philosophicus, em que a significação de uma palavra era dada pela denotação de um objeto, nas Investigações Filosóficas, a significação é gerada no uso das palavras em um jogo de linguagem. É à esse conjunto de palavras e ações que Wittgenstein dá o nome de “jogos de linguagem" (IF $\int$ 7). Ele exemplifica alguns jogos como "[...] comandar e agir segundo comandos - Descrever um objeto conforme a aparência ou conforme medidas Relatar um acontecimento - inventar uma história, representar teatro [...]” (IF \ 23). Em todos eles podemos perceber essa perspectiva pragmática.

Destituindo qualquer pretensão metafísica de fundamentação última da linguagem, para Wittgenstein, não existe um fundamento comum a todos os jogos de linguagem. Eles são simplesmente semelhantes uns aos outros como os membros de uma família. Alguns traços característicos pertencem a determinados jogos, mas estão ausentes em outros. Se na passagem de um jogo qualquer para outro aparece e desaparece um determinado traço característico, também nos diversos e variados jogos de linguagem aparecem e desaparecem traços característicos. Nesse caráter múltiplo e variado dos jogos de linguagem, as únicas conexões que eles possuem, segundo Wittgenstein, são como as semelhanças existentes entre os membros de uma família. Os jogos de linguagem estão aparentados uns com os outros de diversas formas, e é devido a esse parentesco ou a essas "semelhanças de família" (Familienänblichkeiten) (IF \S 67, 77, 108) que são denominados jogos de linguagem. Semelhanças de família são, assim, as semelhanças entre aspectos pertencentes aos diversos elementos que estão sendo comparados nos jogos de linguagem, mas de forma tal que os aspectos semelhantes se distribuem ao acaso por esses elementos. Esses aspectos semelhantes se entrecruzam aleatoriamente, sem necessariamente se repetir uniformemente.

De acordo com Wittgenstein, o uso de uma palavra no interior de um jogo de linguagem não é uma prática indiscriminada, mas regrada, isto é, ainda que relativamente livre, os usos são regidos por regras que distinguem o uso correto do incorreto das palavras nos diversos contextos. Como salientado, essas regras não são apenas linguísticas, mas também pragmáticas envolvendo ações e objetos em seus variados contextos. E é o conjunto dessas regras, que possuem um aspecto dinâmico e estão em contínuo fluxo, que compõe a gramática. Na medida em que a gramática do segundo Wittgenstein, mais que a

${ }^{5}$ Para uma abordagem mais detalhada desses conceitos, cf. Condé, 1998. 
dimensão sintático-semântica - como defendida no Tractatus Logico-Philosophicus e pela tradição da filosofia da linguagem - incorpora aspectos pragmáticos, ela se constitui como uma prática social. Assim, uma regra linguística e pragmática pode apenas constituir-se efetivamente como tal pela práxis social. A gramática é um produto social. Da mesma forma que o uso condiciona a regra, reciprocamente, essa regra, em contrapartida, determinará se o uso está correto ou não. No entanto, na medida em que a gramática é um conjunto de regras que está em aberto, novas regras podem ser acrescentadas, antigas regras alteradas, etc. Essa dinâmica, como veremos, é o que possibilitará a análise de nossos julgamentos de processos que emergem ao acaso, de forma aleatória ou ainda que sejam considerados indeterminados (processos não regrados).

A partir do exposto, podemos concluir que a concepção de gramática do segundo Wittgenstein apresenta, assim, algumas características importantes. Em primeiro lugar, como salientado, podemos destacar que a regra é produto de uma práxis social. A partir dessa concepção, depreende-se que a regra é uma convenção social surgida dessa práxis e que, assim, poderia ser diferente se essa práxis fosse outra (ou ainda poderia alterar-se de uma sociedade - forma de vida - para outra). Na medida em que é uma criação social a regra é uma "invenção". Contudo, é importante salientar que "invenção" aqui não é necessariamente uma construção racional deliberada ou planejada, mas o próprio evolver das ações humanas ou um desdobrar dos jogos de linguagem atendendo às demandas, necessidades e formatos da forma de vida onde ocorrem. Não há uma teleologia na gramática e seus jogos de linguagem. Nesse sentido, as regras da gramática se constituem de forma espontânea e muitas vezes a partir da aleatoriedade ou indeterminismo da ação humana.

Com efeito, a gramática não reflete uma essência transcendental como pretendeu as filosofias tradicionais, mas é o simples fruto das práticas sociais. Sendo uma invenção a gramática é, portanto, uma criação "arbitrária”. Entretanto, essa arbitrariedade não é absoluta, uma vez as regras da gramática têm que manter sua coerência com o conjunto das outras regras, práticas e objetos, isto é, com a gramática como um todo: "se o que é regra se tornasse exceção e o que é exceção, regra, ou se as duas se tornassem fenômenos de frequência mais ou menos igual - então nossos jogos de linguagem normais perderiam seu sentido" (IF \ 142). Com efeito, as regras surgem dos nossos "padrões de comportamento", dos nossos hábitos, costumes e instituições (IF \ 142, 199, 202, 226, 227).

Deste modo, quando compreendemos a regra como produto de um jogo de linguagem em seus contextos e práticas sociais, concluímos pelo caráter operatório da

\footnotetext{
${ }^{6}$ É preciso observar que, para alguns intérpretes das Investigações Filosóficas, a gramática, enquanto conjunto das regras, é algo muito distinto dos jogos de linguagem. Entendo que é muito difícil operar essa separação de modo rígido. Ainda que possamos estabelecer uma distinção entre o que é regra e o que são os objetos e ações que formam um jogo de linguagem, a gramática apenas se constitui na medida em que é o regramento destes jogos. A gramática rege tais jogos. De certa forma, a gramática é uma "propriedade emergente" desses jogos de linguagem. É nesse sentido que podemos falar, em termos metodológicos, de uma "gramática da matemática", uma "gramática das cores", etc., mas não podemos entender, em termos epistemológicos, uma rígida separação, pois se trata de um mesmo mecanismo - é no uso que o signo ganha vida (IF $\int 432$ ). Contudo, entendo que haja uma certa primazia metodológica da gramática, enquanto articuladora dos jogos de linguagem, no sentido em que podemos falar de uma "autonomia da gramática", enquanto um conjunto de "linhas" de regras coordenadas, em contraposição aos jogos que, em certo sentido, são "pontuais". Essas linhas da gramática conectam esses diferentes pontos (usos, jogos, etc.). Mas claro que este é apenas um artifício metodológico e não nos impede de olhar por outro lado e dizer que existem os "jogos de linguagem da matemática", os "jogos de linguagem das cores", etc.
} 
regra. Seguir uma regra é uma operação - esse é o caráter pragmático da regra. "Compreender uma linguagem significa dominar uma técnica" (IF \199). Não é um processo mental isolado. "Acreditar seguir a regra não é seguir a regra. E daí não podermos seguir a regra 'privadamente'; porque, senão, acreditar seguir a regra seria o mesmo que seguir a regra" (IF \202). Enfim, como observado, a gramática repousa em uma perspectiva pragmática.

Para Wittgenstein, existem dois níveis da gramática. A gramática de superfície (Oberflachengrammatik) e a gramática profunda (Tiefengrammatik) (IF \ 664). A gramática de superfície trata das características pontuais e evidentes das expressões, sem levar em consideração o contexto gramatical global (panorâmico) em que tais expressões são geradas, contrariamente à gramática profunda (gramática panorâmica), ${ }^{7}$ isto é, a gramática na qual se engendram as complexas regras de uso da linguagem, no interior da qual se opera, à semelhança de um jogo, a produção de diversas expressões linguísticas e seus significados que em seu conjunto constituem nossa inteligibilidade ou racionalidade dos processos que acessamos pela análise. Assim, a gramática profunda leva em consideração não apenas os aspectos peculiares de um dado jogo de linguagem, mas tudo o que está, de modo mais amplo possível, envolvido na práxis da linguagem como, usos, produção de regras, instituições, comportamentos, objetos, etc.

Ao constituir a nossa racionalidade, o sentido geral da noção de gramática do segundo Wittgenstein, talvez, pudesse ser expresso da seguinte forma: a lógica está expressa nas regras da gramática. Toda possibilidade lógica é gramatical. Para o segundo Wittgenstein, a gramática mais que possibilitar a lógica, ela é a própria lógica. Com efeito, a gramática é que nos diz o que é lógico: o que tem e o que não tem sentido, o que está dentro e o que está fora dos limites do sentido. "Assim, depende inteiramente de nossa gramática o que é (logicamente) dito possível e o que não é" (IF \520). Como consequência, todos os nossos critérios de julgamentos são gramaticais. Como, efetivamente, a gramática é o conjunto das regras erigidas a partir da interação entre linguagem e ações de modo regular. Essa regularidade é que estabelece a norma padrão que instaura inclusive as exceções (IF \142). Com efeito, é a partir da análise da gramática que podemos compreender o que se apresenta não apenas como regularidade, mas como acaso ou aleatório ou mesmo indeterminado (enquanto o que não está regrado). Como consequência, a análise se torna o "caminho real" para a compreensão da gramática, isto é, do que está de acordo ou não com a própria gramática. $\mathrm{Na}$ trilha da análise compreendemos os contornos da gramática.

Isto posto, podemos concluir que a gramática, para o segundo Wittgenstein, constitui um modelo de racionalidade vista como uma rede multidirecional flexível que se estende através de "semelhanças de família" que é holista porque apresenta uma dimensão panorâmica (Übersichtlichkeit) constituindo um tipo de sistema aberto e descentralizado no qual a racionalidade não está assentada em nenhum lugar privilegiado, mas se configura a partir das múltiplas relações no interior do sistema de onde fazemos nossos julgamentos.

\footnotetext{
7 A expressão gramática profunda não procura afirmar as "estruturas essenciais da realidade", como pretendeu a tradição metafísica. Não existe nada oculto além de nossa gramática a nos reger. Como salienta H. Glock, "gramática profunda" pode não ser uma boa expressão uma vez que não se trata de um contraste entre a superfície e a "geologia" das expressões, mas entre o uso local e a geografia global. (Cf. Glock, 1996, p. 154-155). Assim, entendo que seria melhor falarmos de uma "gramática panorâmica". Essa compreensão será de grande importância para entendermos a "análise panorâmica".
} 
Portanto, constituindo o sistema de referência com o qual podemos analisar as regularidades e as exceções, sejam essas aleatórias, como produto do acaso, ou ainda sem qualquer parâmetro de regramento, isto é, indeterminadas.

\section{3- Análise, acaso e indeterminismo na gramática}

Como observado, o que faz sentido e o que não faz é determinado pela gramática (IF \520). A partir dessa perspectiva, a gramática, aliada às interações dos jogos de linguagem, desempenhará um papel fundamental no estabelecimento de todo e qualquer parâmetro de racionalidade e julgamento, a partir dos quais podemos compreender não apenas o que é regular, mas o acaso, o aleatório e o indeterminismo. Um dos fatores importantes para compreendemos como isso se processa, como assinalado, está na análise, não apenas em seu papel terapêutico, mas em sua função panorâmica. Com efeito, no que se segue, inicialmente, procurarei abordar aspectos da análise em suas duas funções para, ao fim, tecer algumas considerações sobre o acaso (aleatório) e o indeterminado.

Embora, de um modo geral, os intérpretes do segundo Wittgenstein tenham acentuado o papel terapêutico da análise, o meu entendimento é o de que podemos ter, pelo menos, os dois aspectos da análise assinalados, isto é, ela pode tanto lançar luz sobre os mal entendidos da gramática, em sua função terapêutica, mas também, em seu aspecto panorâmico, tem a capacidade de nos mostrar o que é constitutivo da gramática. A análise panorâmica, como já observado, nos dá acesso à constituição gramatical em seu conjunto possibilitando-nos captar a essência que está expressa na gramática. Se para Wittgenstein, a gramática diz o que um objeto é, por conseguinte, pela análise da gramática, considerando o conjunto das regras, que estabelecemos a determinação deste objeto singular. Apenas pela análise panorâmica - não por uma análise última - é que sabemos o que algo é, conforme instituído pela gramática. A função terapêutica da análise permite-nos elucidar pontos específicos da gramática, corrigindo-os se estiverem contra a regra gramatical, mas apenas uma análise de conjunto, isto é, panorâmica, nos possibilita saber qual deve ser o regramento que se constitui na referência para a correção apontada pela análise com fins terapêuticos. Apenas pela análise panorâmica podemos dar sustentação à análise terapêutica.

$\mathrm{Na}$ medida em que considera o completo arcabouço da gramática, uma análise panorâmica é também algo complexo em correlação com a própria complexidade da gramática. Os problemas filosóficos emergem justamente quando nos falta essa visão panorâmica (übersehen) e não podemos fazer uma análise panorâmica. Com efeito, existe uma correlação direta entre a gramática e a análise que dela possamos fazer. Como dito, a gramática constitui nossa ideia de racionalidade e isto significa dizer, entre outras coisas, que os nossos critérios de julgamento não se constituem na singularidade de apenas "uma" regra para "um" jogo de linguagem (IF \ 199) no interior da gramática, mas a partir do complexo conjunto das regras que compõem a gramática. Devido a essa complexidade, apenas por uma análise em profundidade - ou de uma análise panorâmica, para sermos coerente com a ideia de uma gramática panorâmica - compreendemos esse complexo processo gramatical com suas inumeráveis regras. Pela análise panorâmica saberemos, desta forma, o que é regular e o que é aleatório na gramática. Assim, ainda que uma 
característica qualquer seja constituída inicialmente de modo aleatório na prática social, se ela permanecer tendo importância por um tempo "suficiente" no jogo de linguagem, isto é, apresente uma regularidade (IF \207), essa característica pode ser tomada como referência desse jogo. Ela torna-se um paradigma do jogo (IF \50) e é incorporada ao seu “fundamento" (Fundament) (SC \558), embora o próprio jogo não seja fundamentado: não é razoável ou não razoável, mas simplesmente "está aí - como a nossa vida" (SC \ 559).

Diferentemente da concepção presente no Tractatus Logico-Philosophicus, no qual a análise era vista como um instrumento para alcançar a essência lógica, isto é, como a busca de um elemento último pela decomposição do elemento mais complexo, ${ }^{8}$ percebemos que, nas Investigações Filosóficas, a análise é vista como a descrição global (panorâmica) do uso das expressões. Não se trata de atingir a "análise última", mas de empreender uma análise possível a partir das articulações gramaticais, em seu maior número de regras possíveis. A análise consiste, assim, na descrição da gramática de nossos jogos de linguagem e seus múltiplos regramentos possíveis. A partir de uma análise "panorâmica" da gramática elaboramos o mapeamento de suas "possibilidades", isto é, compreendemos os "lugares da gramática" que nos permitem correlacionar um lugar particular e o todo da gramática e, assim, saber o que está de acordo com ela e o que não está. Com efeito, a análise panorâmica constitui um tipo de "topografia" da gramática.

Deste modo, vemos que, mas que em sua função terapêutica, a partir da qual encontramos equívocos pontuais e substituímos uma forma de expressão por outra, na análise panorâmica não se trata apenas de "corrigir" a gramática, mas de "compreender" suas múltiplas possibilidades de regramentos. E é, nesse sentido, que ao procurar ter a compreensão do maior número possível de regras da gramática em seu conjunto, a análise panorâmica realiza uma "consideração gramatical" (IF \90). Ainda que inclua os fenômenos naturais presentes nos jogos de linguagem e mesmo que oscile entre o natural e o gramatical (IF \392), a análise panorâmica, enquanto uma análise de conjunto das regras, é uma consideração gramatical. Portanto, é neste sentido que ela não analisa diretamente um fenômeno, mas a adequação das considerações gramaticais que fazemos sobre os fenômenos (IF $\int 90$ ) e sobre a própria gramática, ainda que os fenômenos naturais estejam presentes - pois, para Wittgenstein, se os fatos fossem outros, outros seriam nossos jogos de linguagem (IF \ 142) (SC \ 63). Vemos assim a importância relativa dos fatos, mas isto se dá, certamente, não porque os fatos sejam determinantes, mas porque se constituiriam novos jogos de linguagem a partir de novos fatos e, consequentemente, uma nova consideração gramatical.

Para além de "proposições empíricas", portanto, trata-se de estabelecer “proposições gramaticais”, ou proposições sobre as regras da gramática, (IF \$S 85, 90, 109, 251) que nos permitem compreender a gramática dos jogos de linguagem. Nas "Investigações Filosóficas”, diferentemente do que ocorria no Tractatus Logico-Philosophicus, como salientado, não encontramos a essência pela busca do fim último da análise, mas no conjunto das articulações das regras gramaticais. E são nessas articulações que iremos encontrar a

\footnotetext{
8 Afirma Wittgenstein no Tractatus: "Todo enunciado sobre complexos pode-se decompor em um enunciado sobre as partes constituintes desses complexos e nas proposições que os descrevem completamente" (Tract. 2.0201). "Chamo esses elementos de 'sinais simples'; a proposição de 'completamente analisada"' (Tract. 3.201). "Há uma e apenas uma análise completa da proposição" (Tract. 3.25). "É óbvio que devemos, na análise das proposições, chegar a proposições elementares, que consistem em nomes em ligação imediata" (Tract. 4.221).
} 
essência expressa pela gramática. Portanto, não podemos conceber uma tal análise que busca a essência na gramática a não ser como uma "consideração gramatical". Enfim, embora os jogos de linguagem contenham objetos, fatos, ações e comportamentos, não se trata propriamente de analisar os fenômenos em si, mas a consideração gramatical que fazemos sobre os fenômenos. Isto é o que significa dizer que pela análise não se busca alcançar a análise última ou o fundamento de um fato, mas de estabelecer uma análise das possibilidades de articulação do conjunto da gramática.

Uma vez que os critérios de racionalidade estão encorados na gramática e nos jogos de linguagem, não existem critérios absolutos, uma vez que tais critérios podem mudar com a alteração da dinâmica da gramática como um todo. E, em virtude de a gramática e os jogos de linguagem serem dinâmicos, sempre é necessário a atualização da análise. Em outras palavras, se a gramática se modifica, necessariamente sua análise também se modifica. A análise precisa estabelecer um paralelo com a própria gramática e, assim, ela se torna um importante parâmetro de compreensão do que é estabelecido como referência para a racionalidade. É nesse sentido que a análise panorâmica é o mapeamento das "possibilidades" gramaticais ou das possibilidades de nossa razão (topografia da razão). Com efeito, concluímos que a partir da análise panorâmica pode-se compreender não apenas o que a gramática determina como correto ou não, mas também podem ser aferidos - pelo conjunto das regras da gramática - os parâmetros dessa determinação do que é tido como correto ou não. Portanto, a análise vai além de um procedimento exclusivamente terapêutico, isto é, ela não apenas mostra se o emprego da regra está adequado, mas também como esse procedimento particular encontra sua significação a partir do todo das regras e procedimentos, isto é, da gramática e dos jogos de linguagem. É por isso que não encontramos a essência gramatical pelo fim último da análise, mas na articulação do conjunto das regras que compõem a gramática e aí encontramos expressa sua essência. A análise panorâmica permite, assim, a "visão panorâmica" (übersehen) da gramática e de seus jogos de linguagem em uma forma de vida. A partir desse olhar panorâmico possibilitado pela análise é que sabemos o valor de algo singular no interior da gramática.

Podemos compreender, assim, que a dificuldade da análise é a dificuldade de muitas vezes termos uma falta de visão panorâmica de nossa gramática, isto é, nesse contexto panorâmico da gramática, nem sempre é fácil determinar a "essência" do que se está analisando (IF \62). Uma vez que não se trata de descobrir a "análise última", mas a determinação da "correção" ou "exatidão" do sentido através da análise, não se trata, assim, de dizer que "quem conhece apenas a forma não analisada priva-se da análise; mas quem conhece a forma analisada, possui tudo" (IF \ 63). Isto porque, como assinalado, o que se busca na análise não é a "análise última", mas "uma" análise possível a partir das "possibilidades gramaticais" que determinam o sentido do jogo de linguagem ou a gramática do que está sendo analisado. A análise é, consequentemente, não apenas relativa à gramática, mas possibilitada pela gramática. O fim de uma análise não é encontrar a última elucidação ou o fundamento último, mas a efetivação de uma possibilidade gramatical em um jogo de linguagem. É encontrar um sentido (Wits) na gramática (IF \ $62,120)$.

\footnotetext{
${ }^{9}$ Lembrando que “[...] um ideal de exatidão não está previsto; não sabemos o que devemos nos representar por isso - a menos que você estabeleça o que deve ser assim chamado" (IF \ 88). "Correto e falso é o que os homens dizem; e na linguagem os homens estão de acordo. Não é um acordo sobre as opiniões, mas sobre o modo de Vida” (IF \241).
} 
A partir do conceito de análise peculiar à filosofia analítica, como disse, as interpretações tradicionais de Wittgenstein entenderam que para esse filósofo o papel da filosofia era essencialmente promover um tipo de "análise terapêutica da linguagem" e não, mais que isso, estabelecer uma reflexão sobre as possibilidades da razão ou de uma constituição ontológica. A partir desse contexto de interpretação proveniente da tradição da filosofia analítica, o aspecto exclusivamente "terapêutico" da concepção de análise da linguagem das Investigaçôes Filosóficas passou a ser entendido como um dos pontos centrais do livro. Entretanto, como vimos, a análise não pode ser pensada simplesmente com relação à aplicação de uma regra, mas com relação à aplicação de uma regra no contexto da gramática enquanto conjunto das regras. O que vale dizer que não apenas a gramática possui um aspecto sistêmico, mas a própria análise tem que se adequar a este aspecto sistêmico ou panorâmico. Ainda que a gramática seja extensa (ponorâmica), apenas por uma análise também panorâmica podemos compreender a nossa gramática. Nessa análise podemos "ver" conexões entre os vários domínios da gramática e, assim, realizar "articulações intermediárias" e ter uma noção do todo da gramática. Pois como salienta Wittgenstein,

Uma fonte principal de nossa incompreensão é que não temos visão panorâmica do uso de nossas palavras - falta caráter panorâmico à nossa gramática (...) a representação panorâmica permite a compreensão, que consiste justamente em "ver as conexões". Daí a importância de encontrar e inventar articulações intermediárias. O conceito de representação panorâmica é para nós de importância fundamental. Designa nossa forma de representação, o modo pelo qual vemos as coisas. (É isto uma visão de mundo?) (IF \122).

Em síntese, a análise como uma "visão panorâmica" permite perceber a gramática e os jogos de linguagem como um sistema dinâmico e articulado. A análise possui assim duas funções correlatas. Primeiro, possibilita estabelecer se algo está correto ou não, de acordo com tais e tais regras e usos específicos e com isso eliminar a metafísica, sendo esta a sua função terapêutica. Em sua função panorâmica, a própria possibilidade de realização de toda análise constitui-se a partir da gramática panorâmica, enquanto conjunto de regras, sendo esse o seu aspecto constitutivo ou ontológico. Certamente, ontologia aqui diz respeito à uma ontologia gramatical, visto que a essência está na gramática. É a partir da dimensão panorâmica da gramática que se estabelecem os próprios parâmetros da análise. É nesse sentido, como salientou Wittgenstein, que falhamos na compreensão da linguagem quando nos falta a "visão panorâmica".

A partir do exposto, podemos tecer algumas considerações sobre o acaso (aleatório) e o indeterminado. Longe dos regramentos que constituem as regularidades, o aleatório e o indeterminado estão no limiar da gramática, mas ainda assim podem, eventualmente, serem incorporados pela gramática, isto é, podem ser regrados. Caso não possam, constituirão o lugar do interditado pela gramática. Eu apenas julgo o que não é regular, ou o que é o acaso, a partir do conjunto do meu regramento, isto é, de minha gramática. Mesmo que algo seja fruto do acaso, posso a partir de minha gramática analisálo. Assim surgem muitos dos novos jogos de linguagem, dos novos regramentos. Por ser dinâmica, a gramática está sempre se deparando com o acaso e o aleatório. Se esses são, 
inicialmente, desconhecidos poderão, naturalmente, deixar de ser ao serem analisados pela gramática. Em outros termos, ainda que a análise seja possibilitada pela "gramática panorâmica", em certo sentido, ela pode "ultrapassar" a gramática, isto é, pode ampliá-la, sendo usada para buscar a elucidação de jogos de linguagem de fronteira presentes em gramáticas diferentes ou diferentes formas de vida (Lebensform) (IF \23) através de comparações e interações entre elas, isto é, entre possíveis semelhanças de família entre elas. Deste modo, a análise tem um importante papel na compreensão da gramática como possibilidade de compreensão do que está para além de suas próprias regras e, assim, o que não era regrado passar a sê-lo.

Com isso, não se quer dizer que o regramento de algo que surge ao acaso seja "o" único entendimento desse acaso, mas apenas uma compreensão possível a partir das regras da gramática. $\mathrm{O}$ acaso é sempre regrado a partir da gramática. Apenas a gramática tem a possibilidade de tornar o acaso em um padrão para nossas ações e julgamentos. Algo que se constitui como acaso e que seja, inicialmente, "indeterminado", pela análise torna-se determinado.

No entanto, nem tudo que é indeterminado é aleatório. Com isso quero dizer que a gramática convive com zonas de indeterminação que são constantes. Algumas dessas indeterminações estão nas bordas da gramática e dificilmente são incorporadas. São certos "resíduos" gramaticais. Portanto, o indeterminado pode se configurar como um limite extremo da gramática. Se, em princípio, algo indeterminado (ou não regrado) contenha a possibilidade de ser compreendido (ou regrado), este não é um processo necessário, pois o indeterminado pode continuar, em definitivo, para além dos limites da fronteira da gramática. Existe, com isso, o espaço da não compreensão na gramática. Contudo, ainda assim podemos de algum modo "circunscrever" este indeterminado.

Em outras palavras, mesmo que a gramática não tenha quase nenhuma, ou mesmo nenhuma, semelhança de família com um tal indeterminado, ainda é possível circundá-lo gramaticalmente, mesmo não atingindo o seu núcleo. Talvez, neste caso, a compreensão estabelecida por este processo de se avizinhar seja algo sempre unilateral - a partir de nossa gramática -, mas ainda assim é o estabelecimento de um sentido. Podemos imaginar certas possibilidades desses limites, como por exemplo, um surto psicótico ao qual não podemos "de fora" compreender suas regras "de dentro". Em outras palavras, não faltará na nossa gramática, a partir de suas regras, uma possibilidade de circunscrever tal experiencia psicótica, ainda que não necessariamente possamos determinar a lógica interna presente em um surto psicótico (A não ser tendo um surto psicótico e pressupondo que ele possa internamente ter um regramento).

De modo semelhante, nos encontramos com muitas indeterminações diante da natureza. Estabelecemos "conjecturas" sobre a natureza, como nos ensinou Popper, e pela "gramática da ciência" produzimos nossa compreensão possível sobre ela. Com isto, um comportamento indeterminado da natureza passa a ser determinado por nossa gramática (Certamente, nesse processo os fatos são importantes, mas não determinantes, como salientado). Deste modo, construímos, gradativamente, nosso conhecimento sobre a natureza. Enfim, pela gramática estabelecemos nossa visão de mundo (IF \122). Relativamente à ciência, visão de mundo essa que pela dinâmica da gramática e da natureza se altera com o tempo, mas pela análise panorâmica temos a possibilidade de acompanhar 
as mudanças desse processo e termos a sua compreensão. Enfim, uma análise panorâmica nos permite ampliar nossos conhecimentos.

\section{4- Conclusão}

Neste capítulo, vimos que os conceitos de aleatoriedade e indeterminismo, ainda que não tenham sido trabalhados explicitamente por Wittgenstein, podem ser vistos a partir da sua noção de análise. Existem pelo menos duas funções para a análise: a análise terapêutica e a análise panorâmica. Em outras palavras, a análise dos jogos de linguagem e de sua gramática é o que possibilita tanto a realização de uma terapêutica dos mal entendidos que conduzem à metafísica quanto, em sua função panorâmica, permite a nossa percepção das regularidades das regras gramaticais. Mais que isso, a análise panorâmica, além de nos dar acesso ao novo que se configura como acaso, é ainda um ferramenta para lidarmos com a indeterminação que foge aos regramentos da gramática. A análise panorâmica fornece o acesso à "essência expressa na gramática". Com efeito, mais que uma terapêutica, a análise, em sua função panorâmica, é compreendida como uma "consideração gramatical” sobre as regras da gramática. Por fim, uma tal análise panorâmica se estabelece não apenas como parâmetro de compreensão das regularidades das regras instituídas, mas também é uma instrumento para lidar com o acaso e o indeterminado que se apresentam nas bordas da gramática e, com isso, possibilita a ampliação de nosso conhecimento.

\section{5- Referências}

CONDÉ. M. L. Wittgenstein: Linguagem e Mundo. São Paulo: Annablume, 1998.

GLOCK, J. H. A Wittgenstein Dictionary. Oxford: Blackwell, 1996

\section{WITTGENSTEIN, L. Philosophische Untersuchungen / Philosophical}

Investigations. Trad. M. Anscombe. Oxford: Basil Blackwell, 2008. Publicado inicialmente em 1953.

. Investigações Filosóficas. 2. ed. Trad. J. C. Bruni, São Paulo: Abril Cultural, 1979. Publicado inicialmente em 1953.

. Investigações Filosóficas. Trad. M. G. Montagnoli, Petrópolis: Vozes, 1994. Publicado inicialmente em 1953.

Recherches Philosophiques. Trad. P. Klossowiski, Paris: Gallimard, 1961. Publicado inicialmente em 1953.

Tractatus Logico-Philosophicus. (Português/Alemão), tradução, apresentação e ensaio introdutório, L. H. Lopes dos Santos. São Paulo: Edusp, 1993. Publicado inicialmente em 1921. 
. Über Gewissheit / Sobre a Certeza. Trad. M. Costa. Lisboa: Edições 70, 1990. 